\title{
Mediação e conflito familiar
}

\section{Cristiano Correia de Paula ${ }^{1}$, Fernando Gomes de Menezes ${ }^{2}$, Klauber Guedes Cardoso ${ }^{3}$, Maria Rita Rodrigues Constâncio Menezes $^{2}$,*, Maria Vitória Rodrigues Constâncio Leão ${ }^{4}$ e Suliene Carvalho de Medeiros ${ }^{5}$}

\author{
${ }^{1}$ Rua do Calcário, 4415. Bairro Flodoaldo Pontes Pinto. Porto Velho-R0, Brasil \\ (CEP 76820-694) \\ ${ }^{2}$ Rua Vespasiano Ramos, 3334. Bairro Agenor de Carvalho. Porto Velho-RO, Brasil \\ (CEP 76820-366). *E-mail: mr.constancio15@ymail.com. \\ ${ }^{3}$ Tribunal de Justiça de Rondônia. Rua José Camacho, 585. Olaria. Porto Velho-R0, \\ Brasil (CEP 76801-330). \\ ${ }^{4}$ Rua Pau Ferro, 1721. Castanheira. Porto Velho-RO, Brasil (CEP 76811-483). \\ ${ }^{5}$ Av. Sete de Setembro, 1185. Centro. Porto Velho-RO, Brasil (CEP 76801-097).
}

Resumo. A pesquisa visa a apresentar à sociedade a importância do diálogo nas relações familiares com o uso da mediação e conciliação na solução de conflitos intrafamiliares, conforme o previsto na Lei no 13.140/2015 e no novo Código de Processo Civil. A mediação é a melhor forma para resolver os conflitos, sejam eles familiares ou não, tendo o mediador um importante papel na pacificação social. 0 estudo pretende demonstrar as vantagens do instituto da mediação como alternativa para a solução dos conflitos familiares em contraponto as decisões judiciais, oportunizando assim as partes uma forma alternativa de solução do litígio, garantindo a celeridade e a efetividade das decisões judiciais, bem como a minimização dos desgastes decorrentes do processo judicial na forma tradicional que geralmente leva mais tempo e provoca maiores prejuízos as relações familiares entre as partes envolvidas que guardam magoas e decepções em quanto que a conciliação traz a satisfação e a paz.

Palavras-chave: Mediação; Conciliação; Família; Conflito; Diálogo.

Abstract. Family conflict and mediation. The research aims to present to society the importance of dialogue in family relations with the use of mediation and conciliation in the solution of intrafamilial conflicts, according to the provisions of Law $13,140 / 2015$ and new Code of Civil Procedure. Mediation is the best way to resolve conflicts, whether they are familial or not, and the mediator plays an important role in social peacemaking. The study intends to demonstrate the advantages of the mediation institute as an alternative to the solution of family conflicts in counterpoint to judicial decisions, thus providing the parties with an alternative way of solving the litigation, ensuring the speed
Recebido:

09/02/2019

Aceito:

21/04/2019

Publicado:

$30 / 04 / 2019$

Full Text Article

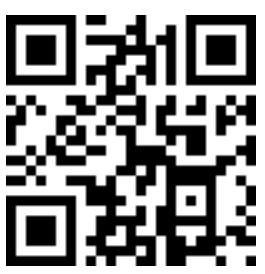

ORCID

(ㄱ) 0000-0003-2774-9640 Cristiano Correia de Paula

(D) 0000-0003-3044-393X Fernando Gomes de Menezes

D) 0000-0003-0967-0193 Klauber Guedes Cardoso

D) 0000-0003-3862-5199 Maria Rita Rodrigues Constâncio Menezes 
and effectiveness of judicial decisions, as well as minimizing the wear and tear resulting from the judicial process in the traditional way that usually takes longer and causes greater harm to family relations between the parties involved who are in pain and disappointment in that conciliation brings satisfaction and peace.

Keywords: Mediation; Conciliation; Family; Conflicts; Dialogue.
D) $0000-0002-2174-7133$

Maria Vitória

Rodrigues Constâncio

Leão

D) 0000-0002-9061-7922

Suliene Carvalho de Medeiros

\section{Introdução}

As mudanças constantes na sociedade requer do Poder Judiciário uma nova forma de atuação na solução dos conflitos, sendo necessário adaptação da justiça à nova realidade diante das inovações sociais e legislativas.

A pesquisa busca apresentar à sociedade a importância do diálogo nas relações familiares, mediante o uso de mecanismos de mediação, para soluções de conflitos. 0 tema encontra-se abordado na Resolução CNJ no 125/2010 (Brasil, 2010), na Lei $\mathrm{n}$ - 13.140/2015 (Lei de Mediação) (Brasil, 2015), e no novo Código de Processo Civil (Lei $\mathrm{n}^{\mathrm{o}}$ 13.105/2015) (Brasil, 2015), que visam a encontrar uma solução equânime e adequada ao caso concreto.

Em 2013, o Poder Judiciário do Estado de Rondônia criou os Centros Judiciários de Solução de Conflitos, por meio da Resolução no TJRO/PR no 008/2013 (Rondônia, 2013), a fim de adequar-se as exigências legais de forma a impulsionar a mediação e/ou conciliação entre as partes na busca da pacificação social.

A mediação é uma alternativa de resolução de conflitos informal e flexível, de caráter voluntário e confidencial, que promove a aproximação entre as partes e apoia o diálogo na busca de acordo que satisfaça ambos os interesses.

A nova sistemática do novo Código de Processo Civil busca facilitar o diálogo entre as partes envolvidas por meio da autocomposição, objetivando a mediação ou a conciliação, com isso busca-se implantar a cultura da pacificação processual e social de forma ética e respeitosa, promovendo a justiça de forma mais célere e harmoniosa.

Deste modo, abordar-se nesta pesquisa as origens dos conflitos familiares, os introdutórios dos mecanismos do instituto da mediação, bem como suas vantagens nos conflitos familiares, a relevância, seus procedimentos e reflexos, a importância e os resultados da mediação e sua sistematização, sobretudo na Comarca de Porto Velho, Rondônia, nas Varas de Família.

Diante disso, este estudo pretende demonstrar as vantagens do instituto da mediação como alternativa para o tratamento dos conflitos familiares, oportunizando as partes, alternativas eficazes para o tratamento de litígios, especialmente diante do abarrotamento de processos no Poder Judiciário, garantindo a celeridade e a efetividade das decisões processuais de acordo com os princípios constitucionais minimizando os desgastes e danos as partes.

A escolha do tema em apreço, além de ser bem atual, pretende ainda, apresentar a importância e a necessidade da conciliação e/ou mediação, como elementos na tentativa de resolução de litígios, auxiliar no entendimento acadêmico de estudantes interessados no tema, bem como, apresentar à sociedade a real função dos institutos em estudo, que nem sempre é entendido pela coletividade.

Objetivo geral do trabalho é analisar a mediação e a conciliação familiar que visa à resolução de conflitos por meio do diálogo, procurando adequar os princípios constitucionais, sobretudo o da dignidade humana, 
priorizando o respeito e os laços familiares. Já os objetivos específicos, é abordar as vantagens do instituto da mediação e da conciliação para o tratamento dos conflitos familiares em contraponto com as decisões judiciais, com a função de dizer o direito. 0 estudo busca responder a seguinte pergunta: os conflitos familiares devem ser resolvidos através de um terceiro mediador, no restabelecimento do diálogo, para atingir o equilíbrio nas resoluções de litígios de maneira informal?

Para tal, foram explorados aspectos inerentes à Constituição Federal (Brasil, 1988), ao Código de Processo Civil (Brasil, 2015), à Lei de Mediação (Lei no 13.140/2015) (Brasil, 2015), bem como à Resolução CNJ no 125/2010 (Brasil, 2010) e à Resolução TJRO/PR no 08/2013 (Rondônia, 2013).

A pesquisa será qualitativa e realizar-se-á por técnicas de coletas de dados por meio de entrevista semiaberta/mista, a fim de aumentar a eficácia e validade do estudo. Serão entrevistados um psicólogo e um juiz da Vara de Família.

Os fundamentos teóricos serão elaborados com respaldados na pesquisa bibliográfica que lançará mão de livros, doutrinas, artigos científicos, jurisprudências, monografias e artigos de periódicos, utilizando-se os descritores "Mediação Conflito Familiar na Comarca de Porto Velho", objetivando a fundamentação teórica do tema.

\section{Conceito e caracterização do conflito}

O termo conflito pode ser definido como um processo ou estado em que duas ou mais pessoas divergem em razão de metas, interesses ou objetivos individuais percebidos como mutuamente incompatíveis. Souza (2013) relata que intuitivamente se aborda o conflito como um fenômeno negativo nas relações sociais que proporciona perdas para, ao menos, uma das partes envolvidas. Em treinamentos de técnicas e habilidades de mediação, os participantes frequentemente são estimulados a indicarem a primeira ideia que lhes vem à mente ao ouvirem a palavra conflito. Em regra, a lista é composta pelas palavras: guerra, briga, disputa, agressão, tristeza, violência, raiva, perda e processo.

Quanto à caracterização do conflito é dissenso. Para Vasconcelos (2008), decorre de expectativas, valores e interesses contrariados. Embora seja contingência da condição humana, e, portanto, algo natural, numa disputa conflituosa costuma-se tratar a outra parte como adversário, infiel ou inimiga. Cada uma das partes da disputa tende a concentrar todo o raciocínio e elementos de prova na busca de novos fundamentos para reforçar a sua posição unilateral, na tentativa de enfraquecer ou destruir os argumentos da outra parte. Esse estado emocional estimula as polaridades e dificulta a percepção do interesse comum.

A consciência do conflito como fenômeno inerente à condição humana é muito importante. Sem essa, tendemos a demonizá-la ou a fazer de conta que não existe.

A solução transformadora do conflito depende do reconhecimento das diferenças e da identificação dos interesses comuns e contraditórios subjacentes.

Em suma, as relações, com sua pluralidade de percepções, sentimentos crenças e interesses, são conflituosas. A negociação desses conflitos é um labor comunicativo, quotidiano, em nossas vidas.

\section{Mediação e conciliação}

Para Scavone Junior (2014), tanto a Mediação como a Conciliação são mecanismos que auxiliam na resolução de conflitos. Sendo a Mediação uma atividade técnica exercida por terceiro imparcial e sem poder decisório, que, escolhido ou aceito pelas partes, as auxilia e estimula a identificar ou desenvolver soluções consensuais para a 
controvérsia (Lei no 13.140/2015, art. 1ํㅡㄹ parágrafo único).

Por outro lado, a Conciliação implica a atividade do conciliador que atua na tentativa de obtenção da solução dos conflitos sugerindo a solução sem que possa impor sua sugestão compulsoriamente. 0 conciliador tenta devolver as partes a solucionar o conflito acatando suas ponderações e alternativas para a resolução do conflito que, entretanto, depende da anuência das partes.

Centros judiciários de solução consensual de demandas (Código de Processo Civil, art. 165, $\S \S 2^{\circ}$ e $3^{\circ}$, Lei no 13.140/2015) criados pelos tribunais são responsáveis pelas audiências de conciliação e de mediação, havendo estranha determinação para que haja utilização de: a) mediação: preferencialmente quando houver vínculo social anterior prolongado entre as partes; e, b) conciliação: preferencialmente quando não houver vínculo anterior entre as partes ou, havendo, não for vínculo social prolongado.

\section{Princípios que regem a} mediação e a conciliação. De acordo com Tartuce (2018) a observância dos princípios da mediação é crucial para que sua prática seja realizada de forma adequada em proveito das pessoas em crise. Jurisdicionados e advogados brasileiros padeceram de muitas mazelas ao longo dos anos por conta de práticas enviesadas que, apesar de denominadas conciliatórias, não respeitavam princípios nem técnicas, revelando uma perversa busca de extinção de processos judiciais a qualquer custo.

No âmbito público foram traçadas diretrizes importantes pela Resolução no 125, do Conselho Nacional de Justiça, que instituiu a Política Judiciária Nacional de tratamento de conflitos de interesses tendente a assegurar a todos o direito à solução dos conflitos por meios adequados à sua natureza e à sua peculiaridade. As previsões da resolução mencionam conjuntamente a mediação e a conciliação; apesar de traçar diretrizes éticas e princípios, o ato normativo não definiu os meios consensuais.

No plano normativo a relevância dos princípios tem sido amplamente reconhecida. 0 Código de Processo Civil (Lei $\mathrm{n}$ - 13.105/2015), em seu art. 2o ${ }^{\circ}$, que, mais do que princípios norteadores da mediação, começa a esboçar novos conceitos dentro do ordenamento jurídico brasileiro, que são: a) imparcialidade do mediador; b) isonomia entre as partes; c) oralidade; d) informalidade; e) autonomia da vontade das partes; f) busca do consenso; g) confidencialidade; h) boa-fé.

Por conseguinte, o art. 166, do Código de Processo Civil, serem princípios regentes da mediação e da conciliação em juízo a independência, a imparcialidade, a autonomia da vontade, a confidencialidade, a oralidade, a informalidade e a decisão informada.

O novo Código de Processo Civil contempla previsão sobre a atuação do mediador: ao atuar preferencialmente nos casos em que houver vínculo anterior entre as partes, ele auxiliará os interessados a compreender as questões e os interesses em conflito de modo que eles possam, pelo restabelecimento da comunicação, identificar por si mesmos, soluções consensuais que gerem benefícios mútuos.

A lei de mediação brasileira (Lei no $13.140 / 2015$ ) considera tal meio como a atividade técnica exercida por um terceiro imparcial sem poder decisório, que, escolhido ou aceito pelas partes, as auxilia e estimula a identificar ou desenvolver soluções consensuais para a controvérsia.

As definições indicam que a mediação busca proporcionar um espaço qualificado de conversação que permita a ampliação de percepções e propicie ângulos plurais de análise aos envolvidos.

Por fim, a Constituição Federal (Brasil, 1988) considera cláusula pétrea o princípio da dignidade pessoa humana 
que está inserido no inciso III, art. 1ํ․ Nas palavras de Fachin "Trata-se daquilo que se denomina princípio máximo, ou superprincípio, ou macro-princípcio, ou principio dos princípios. Diante desse regramento inafastável de proteção da pessoa humana é que está em voga, atualmente, falar em personalização, repersonalização e despatrimonialização do Direito privado".

Menciona Tartuce (2018), na concepção de dignidade humana, deve-se ter em mente a construção de Kant, segundo a qual se trata de um imperativo categórico que considera a pessoa humana como um ser racional, um fim em si mesmo (Silva, 2017).

De acordo com a Constituição Federal (Brasil, 1988), o direito de família passou por significativas mudanças que colocaram fim a ideia de que a família era apenas constituída por meio do casamento e com fins patrimoniais. Tem-se que a carta magna reconheceu outros modelos de família, dentre elas a formada por meio da união estável e aquela formada por um dos pais e os filhos. Ocorreu à positivação de princípios norteadores do Direito das Famílias, como preceitua o art. 226, em um rol não taxativo, in verbis:

Art. 226. A família, base da sociedade, tem especial proteção do Estado.

$\S 1^{\circ} 0$ casamento é civil e gratuita a celebração.

$\S 2$ o 0 casamento religioso tem efeito civil, nos termos da lei.

§ 3ำ Para efeito da proteção do Estado, é reconhecida a união estável entre o homem e a mulher como entidade familiar, devendo a lei facilitar sua conversão em casamento.

$\S$ 4o Entende-se, também, como entidade familiar a comunidade formada por qualquer dos pais e seus descendentes.

$\S 50$ Os direitos e deveres referentes à sociedade conjugal são exercidos igualmente pelo homem e pela mulher.

$\S 6^{\circ}$ O casamento civil pode ser dissolvido pelo divórcio. (Redação dada Pela Emenda Constitucional $\mathrm{n}^{\underline{0}}$ 66, de 2010).

$\S 7$ 7ํ Fundado nos princípios da dignidade da pessoa humana e da paternidade responsável, o planejamento familiar é livre decisão do casal, competindo ao Estado propiciar recursos educacionais e científicos para o exercício desse direito, vedada qualquer forma coercitiva por parte de instituições oficiais ou privadas.

$\S \quad 8^{0} \quad 0$ Estado assegurará a assistência à família na pessoa de cada um dos que a integram, criando mecanismos para coibir a violência no âmbito de suas relações. (Brasil, 1988).

Segundo Lôbo (2002), os princípios jurídicos aplicáveis ao Direito de Família e a todas as entidades familiares podem ser agrupados, para fins didáticos em princípios fundamentais e princípios gerais. Os princípios fundamentais seriam os da dignidade da pessoa humana e da solidariedade; já os princípios gerais seriam os da igualdade, liberdade, afetividade, convivência familiar e melhor interesse da criança (Lima, 2017).

\section{Mediação familiar}

O Direito de Família pode ser considerado o mais humano dos ramos jurídicos; afinal, trabalha valores personalíssimos e busca dar segurança e proteção à pessoa desde o seu nascimento, assegurando o respeito à sua dignidade (Tartuci, 2018).

Nas relações familiares, o afeto revela-se um ponto nuclear, o que gera especificidades consideráveis no trato do tema. Inicialmente, as entidades familiares eram focadas na relação de 
poder (e dominação) dos pais em relação aos filhos.

A partir de significativas mudanças verificadas no tecido social, passaram-se a conceber tais relações em sua índole afetiva; todavia, há constante tensão entre a configuração da família ora como relação de poder, ora como de afeto. Por tal razão, ao civilista compete abordar a temática com especial atenção a valores subjetivos relevantes $\mathrm{e}$ complexos como o afeto e a proteção (Tartuci, 2018).

Além do que, os conflitos familiares se diferenciam de outros tipos de conflitos em razão de suas peculiaridades. Assim, considerando tais peculiaridades, faz-se necessário uma forma diferenciada para a resolução destes litígios familiares, sendo que a mediação familiar se apresenta como o meio mais apropriado para o tratamento de conflitos em família (Lima, 2017).

Como já supradito antes, a mediação é um processo informal. Ela leva os envolvidos a construírem suas próprias decisões, que devem ser mutuamente aceitas, possibilitando a continuidade da relação, prevenindo qualquer tipo de inimizade. Nos conflitos familiares as questões a serem resolvidas são complexas, e a família consegue reestabelecer a comunicação com a mediação, sendo que essa técnica ajuda na resolução de questões emocionais, sendo a vingança deixada de lado para dar lugar ao bom senso (Lima, 2017).

\section{Previsões legais}

$\begin{array}{ccccc}\text { Mediação } & \text { e } & \text { conciliação } & \text { no } \\ \text { processo civil e } & \text { na Lei } & \text { no }\end{array}$
13.140/2015. O novo Código de Processo Civil (CPC), em seu art. 334, trata especificamente da audiência de conciliação ou mediação. Nos sete artigos presentes no Capítulo dedicado às "Ações de Família" (art. 693 a 699) não tratam majoritariamente da adaptação de mecanismos processuais aos processos que envolvem demandas familiares (com exceção dos arts. 698 e 699), mas sim do fomento ao consenso nesses casos e da inserção de algumas regras peculiares a este tipo de demanda (Tartuci, 2018).

A primeira diretriz voltada ao consenso consta no art. 694, segundo a qual "todos os esforços serão empreendidos para a solução consensual da controvérsia". A previsão é salutar, já que é essencial disponibilizar elementos para que os membros da família possam reforçar tal instituição de forma que ela mesma supra suas necessidades sem precisar delegar a solução de suas crises a terceiros. Vale destacar, porém, que o "empreendimento de esforços" deve se verificar sem qualquer coerção para que as partes aceitem participar das sessões consensuais (Tartuci, 2018).

A interdisciplinaridade dos meios consensuais está reconhecida no dispositivo, que determina que o juiz deve dispor "do auxílio de profissionais de outras áreas de conhecimento para a mediação e conciliação (Tartuci, 2018).

A requerimento das partes ou do mediador, e com anuência daquelas, poderão ser admitidos outros mediadores para funcionar no mesmo procedimento quando isso for recomendável em razão da natureza e da complexidade do conflito (Lei $\mathrm{n}^{\text {o }}$ 13.140/2015, art. 15). Recomenda-se a atuação conjunta, por exemplo, quando se revelar pertinente contar com facilitadores de diferentes gêneros e formações. O parágrafo único, do art. 694, do novo Código de Processo Civil (Lei no 13.105/2015) (Brasil, 2015), dispõe que, a requerimento das partes, o processo poderá ser suspenso enquanto as partes se submetem à mediação extrajudicial, reconhecendo a importância do desenvolvimento de tal atividade também fora do controle do Poder Judiciário (Tartuci, 2018, p. 360).

Resolução CNJ no 125/2010 e a Resolução TJRO/PR no 08/2013. 0 Conselho Nacional de Justiça editou a Resolução no 125/2010, que dispõe sobre a conciliação e a mediação partiram de uma premissa de que cabe 
ao Judiciário estabelecer política pública de tratamento adequado dos conflitos de interesses resolvidos no seu âmbito, seja por meio heterocompositivos, seja por meios autocompositivos. Esta orientação veio para organizar, em todo o território nacional, não somente os serviços prestados nos cursos da relação processual (atividades processuais), como também os que possam incentivar a atividade do Poder Judiciário de prevenção de demandas com as chamadas atividades pré-processuais de conciliação e mediação (Azevedo, 2013).

É interessante ressaltar que essa resolução ao instituir a criação de núcleos e centros de solução de conflitos em todos os tribunais brasileiros, dispõe em seus art. 9o e 12 a importância de treinamentos e capacitação dos envolvidos no processo de implementação desta prática, mediação judicial, isto é, a necessidade de capacitar os mediadores e os conciliadores nessa nova metodologia de resolução de litígios para que sua prática seja eficaz e transformadora para todos os protagonistas envolvidos.

O Poder Judiciário de Rondônia instituiu os Centros Judiciários de Solução de Conflitos e Cidadania, por meio da Resolução TJRO/PR no 08/2013, estabelecendo suas competências e procedimentos.

Essa medida visa a promover a prévia mediação ou conciliação entre as partes, estando no art. $7^{\circ}$ a previsão legal da aplicabilidade deste procedimento no Direito de Família no Estado de Rondônia.

A Resolução CNJ no 125/2010 veio viabilizar o acesso à justiça, para atingir a pacificação social, por meio da solução e prevenção de conflitos e na busca do acesso à justiça como uma ordem jurídica justa. Desta forma, a Resolução CNJ no 125/2010, em seu art. $2^{\circ}$, enfatiza a relevância da adequada formação e treinamento de servidores, conciliadores, mediadores, com vistas a boa qualidade dos serviços, nos núcleos e centros.
Além do mais, buscou assegurar ainda que nas Escolas da Magistratura, tanto nos cursos de iniciação funcional, como nos cursos de aperfeiçoamento e ainda nas especializações, que houvesse em suas grades, módulos e disciplinas destinadas aos métodos consensuais de solução de conflitos. Além da busca de parcerias e interlocução com a Ordem dos Advogados, Defensorias Públicas, Procuradorias e Ministério Público, estimulando a participação nos Centros Judiciais de Solução de Conflitos, Cidadania para valorizar a atuação na prevenção dos litígios.

\section{Mediação e conciliação na Comarca de Porto Velho}

O Poder Judiciário de Rondônia instituiu, por meio da Resolução $\mathrm{n}$ o TJRO/PR no 008/2013, os Centros Judiciários de Solução de Conflitos e Cidadania. Especificamente em Porto Velho há três centros - Cível, de Família e Criminal e dos Juizados Especiais. 0 centro de conciliação de família e criminal é composto por cinco Conciliadores e um Chefe do Centro de Conciliação estando a unidade subordinada ao juiz Coordenador que exerce a administração e supervisão dos trabalhos desenvolvidos pela equipe.

Registra-se que em uma visita in locus, no Tribunal de Justiça de Porto Velho, na Vara de Família de Porto Velho, coletou-se a informação de que a Mediação e Conciliação Familiar, encontra-se em fase de implementação, embora já exista no Núcleo Psicossocial de apoio as Varas de Família. Atualmente, no Poder Judiciário existem quatro Varas de Família, onde ocorrem as Mediações Familiares. Esse projeto está sendo acompanhado por magistrados, que tiveram como projeto piloto a Constelação Familiar, antes da mediação, inclusive com as famílias que querem participar da mediação. É realizado levantamento dos processos para se obtiver um parâmetro e o quantitativo de litígios, só então, essas famílias são 
convocadas, à se apresentarem nas Varas para participarem da Conciliação Familiar, para depois essas família participarem da Mediação e da Conciliação. Nesse primeiro momento, recebem todas as informações sobre o mecanismo desse instituto.

A importância destas famílias participarem da Conciliação Familiar, antes da Mediação e da Conciliação é para diagnosticar se elas estão propensas, de forma voluntária a participarem desse mecanismo de solução de litígios.

Observa-se que quando as famílias participam da Constelação familiar, elas são mais propícias a acatarem a solução pacífica dos litígios, e a manutenção e o restabelecimento do vínculo familiar a partir da Mediação e da Conciliação. Entretanto, ainda é um Projeto piloto que está em fase de experimentação.

\section{Procedimentos da mediação familiar}

O novo Código de Processo Civil (Lei no 13.105/2015) (Brasil, 2015) traz regras especiais a respeito das ações de Direito de Família, entre os seus arts. 693 a 699, normas que têm plena incidência para as ações de dissolução do casamento, nos termos da lei. Os preceitos procuraram incentivar a mediação e a conciliação entre as partes, sendo certo que "nas ações de família, todos os esforços serão empreendidos para a solução consensual da controvérsia, devendo o juiz dispor do auxílio de profissionais de outras áreas de conhecimento para a mediação e conciliação" (art. 694, do novo Código de Processo Civil, Lei no 13.105/2015) (Tartuci, 2018: 137).

Com esta finalidade, estabelece o preceito posterior que, recebida a petição inicial e, se for o caso, tomadas as providências referentes à tutela provisória, o juiz ordenará a citação do réu para comparecer à audiência de mediação e conciliação (art. 695, do novo
Código de Processo Civil, Lei $\mathrm{n}^{\mathrm{o}}$ 13.105/2015). Assim, parece claro, pelo dispositivo, que a audiência de mediação e de conciliação tornou-se obrigatória em tais demandas de Direito de Família (Tartuci, 2018).

Todavia, infelizmente, a maioria dos Tribunais de Justiça ainda não criou ou não investiu, de forma satisfatória, nos Centros Judiciários de Solução de Conflitos e Cidadania, o que tem afastado a efetivação dos institutos da mediação e da conciliação.

No último ano, muitas foram às decisões judiciais que chegaram ao nosso conhecimento, declinando a mediação e a conciliação por falta de estrutura, o que representa uma infeliz realidade.

No Poder Judiciário de Rondônia essa realidade é diferente devido à criação dos centros de conciliação, os cursos destinados a servidores e magistrados que vem incentivando e orientando os procedimentos para conciliação e mediação. Em Rondônia foram realizados cursos sobre constelação familiar aos Juízes objetivando a humanização das relações sociais e familiares, bem como a compreensão dos conflitos, fato este que vem contribuir com o processo conciliatório, principalmente com a aplicação do projeto piloto à Constelação Familiar, antes da mediação.

Assim, acredita-se que devido às particularidades dos conflitos familiares, a mediação é uma das formas na resolução de confusões, intrigas mais indicado para tal situação.

Neste estudo elaborou-se uma análise mais acurada dos procedimentos desse instrumento.

Pré-reuniões. Em verdade, como nas demais escolas de mediação, esta é a fase de pré-mediação. 0 encontro de mediação deve ser precedido de reuniões para dar a conhecer a cada uma das partes, isoladamente, as características do processo de mediação, explicar a respeito da confidencialidade, firmar o acordo de confidencialidade, explicar as 
razões da gravação em vídeo (se for o caso), firmar o acordo de aceitação da gravação em vídeo (se necessário), ajustar honorários e definir a questão do tempo disponível. Nesse modelo de mediação, o mediador deve estar acompanhado, necessariamente, de um comediador. As pré-reuniões são, portanto, preparatórias, com vistas à boa condução dos encontros subsequentes (Vasconcelos, 2008).

\section{Primeira etapa - Reunião}

conjunta. A primeira etapa se inicia quando, numa reunião conjunta, em que os mediadores e mediandos devem estar sentados em cadeiras iguais e em círculo, as explicações sobre o processo são reforçadas. Os mediadores esclarecem que as pessoas não devem ser interrompidas e que qualquer uma a qualquer momento pode abandonar o processo, livremente. Deve--se, então, assinar o Termo Inicial de Mediação, conforme já comentado neste capítulo. Iniciam-se as narrativas. Em continuidade, os mediadores já solicitam a apresentação de alternativas, trabalhando a circularidade e a interdependência. Assim, a meta inicial dos mediadores e as suas primeiras frases devem estar voltadas para definir a questão como uma questão compartilhada. E assentar que a mediação é uma oportunidade para trabalhar sobre as questões.

\section{Segunda etapa - Reuniões} individuais. Esse modelo trabalha, fortemente, com as reuniões individuais, em separado. As reuniões individuais, que são consideradas como segunda etapa, ocorrem repetidas vezes, conforme as necessidades que vão sendo verificadas. Elas permitem uma interação mais reservada com cada uma das partes, de modo privado e equitativo, com vistas ao esclarecimento das questões, à identificação de objetivos, necessidades e desejos, à validação de sentimentos e troca de papéis, a evitar a juridicização dos temas ou discursos sobre direitos, e, assim, circularizar, reposicionar e facilitar soluções. 0 que é comunicado nas reuniões individuais não pode ser informado ao outro mediando, salvo autorização expressa.

Terceira etapa - Reunião da equipe. Na mediação circular-narrativa, os mediadores costumam contar com uma equipe de mediadores de apoio, conhecida como equipe reflexiva, que na maior parte do tempo permanece em uma cabine com espelho de visão unilateral. Os mediandos são previamente informados dessa presença. 0 momento em que se reúnem o mediador e o comediador com a equipe reflexiva é tido como terceira etapa. Esta situação ocorre quando o mediador, que sempre trabalha com o apoio de comediador, recebe, na sala de mediação, na presença dos mediandos, os integrantes dessa equipe e com ela troca ideias a respeito do andamento do processo, permanecendo ali os mediandos como simples observadores, escutando o que o grupo de mediadores conversa a respeito do problema e dos comportamentos respectivos (Vasconcelos, 2008).

Concluído esse encontro, os integrantes da equipe reflexiva ausentam-se e tem continuidade $o$ encontro como quarta etapa. É comum a adoção de grupos de quatro mediadores, sendo dois na mediação/comediação e dois na equipe reflexiva. 0 objetivo da reunião interna é ampliar a reflexão para a construção da história alternativa, tendo-se o cuidado de legitimar as pessoas, para que não se sintam em posição negativa, e contextualizar o conflito, expandindo as possibilidades.

\section{Quarta etapa como reunião} conjunta de fechamento. A quarta e última etapa é realizada em uma reunião conjunta em que se consolida e narra à história alternativa e se procura construir o acordo a partir das opções, com avaliação de vantagens e desvantagens, em busca de uma solução 
nova. Finaliza, se for o caso, com a redação de Termo Final de Mediação, com acordo provisório ou não, e que deve ser redigido com posicionamentos positivos, de forma clara, fixando condutas a serem observadas e estabelecendo critérios para uma futura avaliação desse acordo.

Em suma, é necessário reconhecer que o direito à constituição da família é um direito fundamental para que a pessoa concretize a sua dignidade $e$ se estabeleça como ser humano na sociedade.

0 resultado obtido pode ser de fato o esperado, principalmente quando houver esforço em conjunto. Desta forma, a mediação tem suas bases na cooperação entre os conflitantes, e com o auxilio do mediador.

\section{Considerações finais}

Com tudo o que foi exposto, notase, em primeiro lugar, a fundamental importância do papel da mediação para a sociedade. Esta é responsável por dirimir uma série de conflitos de forma célere, promovendo o bem-estar para as partes conflitantes desafogando o judiciário.

Assim verificou-se que a mediação é um importante instrumento de apoio na solução do litigio de forma a restaurar a relação entre as partes envolvidas. 0 mediador e as partes se relacionam sem hierarquia, onde ambos assumem o compromisso de se respeitarem, na busca eficaz da solução da demanda.

Observou-se no estudo que a informalidade e a oralidade da mediação torna o procedimento mais rápido, eficiente e possibilita, ainda, o restabelecimento da comunicação e/ou relações amistosa entre os envolvidos.

Dessa forma obteve-se a resposta à pergunta suscitada no início da pesquisa sobre: os conflitos familiares devem ser resolvidos através de um terceiro mediador, no restabelecimento do diálogo, para atingir o equilíbrio nas resoluções de litígios de maneira informal?

Com o presente estudo constatou-se que os mecanismos da mediação e da conciliação familiar, em muitos estados, encontra-se em fase de implementação e/ou de experimentação, como é o caso de Rondônia, sendo o método uma ferramenta eficaz para solução do litigio, tendo em vista o vínculo existente entre os conflitantes e os sentimentos dos envolvidos, pois a relação familiar vai além de mero interesses processuais devendo ser mantidas, mesmo nos casos em que o núcleo familiar deva ser desconstituído, seguindo cada uma das partes seu destino respeitando-se e cumprindo-se o acordo construído conjuntamente evitando o desgaste processual.

Portanto, a partir desse estudo, conclui-se que esse procedimento é viável e deve ser aplicado, na intervenção de conflitos, sobretudo familiar, tendo a constelação familiar um importante papel para no sucesso da conciliação e restabelecimento da comunicação.

Importante salientar que o mediador, também, é uma peça chave no auxílio para solução desses conflitos, devendo primar pela a ética profissional e os princípios da mediação na busca da pacificação do conflito, devendo haver constante preparação dos profissionais com capacitação que permitam lidar com os diversos conflitos de natureza familiar.

Verificou-se que a Resolução CNJ no 125/2010, o Novo Código de Processo Civil, juntamente com a Lei da Mediação (Lei $\mathrm{n}$ - 13.140/2015), são normas que legitimam a criação e a implementação de Núcleo de Mediação e da Conciliação de conflitos no âmbito do Poder Judiciário, requerendo a efetivação desses mecanismos para oferecer a população esses serviços de forma adequada e qualificada, sendo que em Rondônia o centro de conciliação e mediação foi instituído pela Resolução TJRO/PR no 008/2013 e encontra-se em 
pleno funcionamento no âmbito das Varas de Familiar na Comarca de Porto Velho.

Por fim, destaca-se a importância dos operadores do direito terem em mente que a sua principal missão é a busca constante de um resultado satisfatório para as partes com o intuito de obter o bem estar social para os envolvidas e interessados na demanda processual.

\section{Conflito de interesses}

Os autores declaram não haver conflito de interesses.

\section{Referências}

Azevedo, A. G. (Org.). Manual de mediação judicial. Brasília: PNUD, 2013.

Brasil. Constituição da República Federativa do Brasil de 1988. Disponível em: <http://www.planalto.gov.br/ccivil_03/ constituicao/constituicaocompilado.htm>.

Acesso em: 10 nov. 2018.

Brasil. Decreto-Lei no 4.657, de 4 de setembro de 1942. Lei de Introdução às Normas do Direito Brasileiro. Disponível em: <http://www.planalto.gov.br/ccivil_03/decr eto-lei/Del4657compilado.htm>. Acesso em: 10 nov. 2018.

Brasil. Lei no 13.105, de 16 de março de 2015. Código de Processo Civil. Disponível em: <http://www.planalto.gov.br/ccivil_03/ _Ato2015-2018/2015/Lei/L13105.htm>.

Acesso em: 10 jan. 2019.

Brasil. Lei no 13.140, de 26 de junho de 2015. Dispõe sobre a mediação entre particulares como meio de solução de controvérsias e sobre a autocomposição de conflitos no âmbito da administração pública; altera a Lei $\mathrm{n}^{\mathrm{o}}$ 9.469, de 10 de julho de 1997, e o Decreto no 70.235 , de 6 de março de 1972; e revoga o $\S 2^{\circ}$ do art. 6o da Lei $\mathrm{n}^{\circ}$ 9.469, de 10 de julho de 1997. Disponível em: <http://www.planalto.gov.br/ccivil_03/_ato2 015-2018/2015/Lei/L13140.htm>. Acesso em: 10 jan 2019.
Brasil. Resolução no 125, de 29 de novembro de 2010. Dispõe sobre a Política Judiciária Nacional de tratamento adequado dos conflitos de interesses no âmbito do Poder Judiciário e dá outras providências. Disponível em: <http://www.cnj.jus.br/ busca-atos-adm?documento $=2579>$. Acesso em: 10 jan. 2019.

Lima, L. R. M. A mediação no Direito de Família. Rio de Janeiro: Universidade Federal do Estado do Rio de Janeiro, Escola de Ciências Jurídicas, 2017. (Trabalho de conclusão de curso). Disponível em: <http://www.unirio.br/unirio/ccjp/arquivos /tcc/2017-1-monografia-lara-da-rochamartins-de-lima>. Acesso em: 10 nov. 2018.

Lôbo, P.L.N. Entidades familiares constitucionalizadas: para além do numerus clausus. Jus Navigandi, ano 7, n. 53, 2002. Disponível em: <http://jus.com.br/ revista/texto/2552>. Acesso em: 10 nov. 2018.

Rondônia. Resolução no 008/2013-PR. Dispõe sobre a criação de Centros Judiciários de Solução de Conflitos e Cidadania no âmbito deste Poder Judiciário, estabelece suas competências e procedimentos, bem como de seus juízes coordenadores, conciliadores e pessoal de apoio e dá outras providências. Disponível em: <https://www.tjro.jus.br/images/RESOLUÇÃ O_N._008.2013-PR_-_Consolidada.pdf>.

Acesso em: 10 jan. 2019.

Scavone Junior, L. A. Manual de arbitragem: mediação e conciliação. 5. ed. Rio de Janeiro: Forense, 2014.

Silva, D. L. A. Mediação aplicada ao Direito de Família: Centro de Estudos e Conflitos e Cidadania do Tribunal de Justiça do Estado de Minas Gerais. Sabará: Faculdade de Sabará, 2017. (Trabalho de conclusão de curso). Disponível em: <https://www.faculdadesabara.com.br/medi a/attachments/monografias/TCC-FINALPRONTO.pdf>. Acesso em: 10 nov. 2018.

Souza, A. H. Manual de Mediação Judicial. Brasília: Ministério da Justiça, 2013.

Tartuci, F. Mediação nos conflitos civis. 4. ed. Rio de Janeiro: Forense, São Paulo: Método, 2018. 
Vasconcelos, C. E. Mediação de conflitos e práticas restaurativas. São Paulo: Método, 2008.

\footnotetext{
(CC) Informação da Licença: Este é um artigo Open Access distribuído sob os termos da Licença Creative Commons seja devidamente citada.
} 